\title{
PELATIHAN KEWIRAUSAHAAN DAN PEMASARAN USAHA KECIL MENENGAH PADA MASYARAKAT NAGARI SUNGAI CUBADAK
}

\author{
${ }^{1)}$ Yentisna, ${ }^{2)}$ Yofina Mulyati, ${ }^{3)}$ Alvin Alfian \\ 1,2,3,)Fakultas Ekonomi Dan Bisnis Universitas Dharma Andalas Padang \\ $\underline{\text { Yentisnayen@gmail.com }}$
}

\begin{abstract}
Abstrak
Menumbuhkan minat masyarakat untuk berwirausaha merupakan salah satu tantangan, bagaimana tim pengabdian akan membuka mata masyarakat supaya bisa punya usaha untuk membantu keungan keluarga di Nagari Persiapan Pemekaran Sungai Cubadak di Kecamatan Baso Kabupaten Agam. Dan juga bagaiman menaikkan pendapatan dan produksi usaha kecil menengah yang ada di nagari Sungai Cubadak ini. Sebagian besar mata pencarian masyarakatnya adalah petani selain itu juga ada yang menjadi pedagang makanan dan usaha kecil lainnya. MasyarakatNagari Sungai Cubadak bukan masyarakat yang makmur secara pendapatan. Mengadakan PKM di Nagari Sungai Cubadak dikarenakan masyarakat belum mengerti tentang arti sebenarnya dari membuka usaha kecil menengah, mereka hanya menitik beratkan usaha pada laba, pengetahuan tentang modal rendah yaitu mereka menganggap uang adalah segalanya yang dapat membuat usaha kecil menengah berhasil. Sebagai dosen FEB-UNIDHA, penulis bertujuan memberikan edukasi pada masyarakat Nagari Sungai Cubadak terutama yang mempunyai usaha dan tertarik untuk membuka usaha kecil menengah untuk lebih dapat mengembangkan lagi usahanya dan memberikan pelatihan pengetahuan mengenai kewirausahaan juga pemasaran. Metode yang digunakan adalah pelatihan berbentuk workshop mengenai kewirausahaan dan pemasaran. Sehingga masyarakat bisa meningkatkan pengetahuannya tentang penegelolaan usahanya.
\end{abstract}

Katakunci: Masyarakat Nagari Sungai Cubadak, Kewirausahaan, Usaha Kecil Menengah 


\section{PENDAHULUAN}

Nagari Persiapan Sungai Cubadak merupakan Nagari Pemekaran dari Nagari Tabek Panjang di Kecamatan Baso Kabupaten Agam.Cakupan wilayah Nagari Persiapan Sungai Cubadak meliputi Sungai Cubadak, Balerong Panjang dan Sungai Lamak.Secara administrasi Nagari Persiapan Sungai Cubadak merupakan bagian dari Kecamatan Baso. Nagari Persiapan Sungai Cubadak sebelah barat berbatasan dengan Nagari Padang Tarok, sebelah timur dengan Nagari Tabek Panjang, sebelah utara dengan Nagari Simarasok dan sebelah selatan berbatasan dengan Nagari Koto Tinggi.

Pembentukan Nagari Persiapan Sungai Cubadak disahkan Bupati Agam dengan Peraturan Bupati Agam nomor 12 Tahun 2017 tentang Pembentukan Nagari Persiapan Sungai Cubadak. Surat Keputusan Bupati Agam Nomor 540 Tahun 2017 tentang Pengangkatan Penjabat Walinagari Persiapan Sungai Cubadak Kecamatan Baso, yang mana penjabat walinagari pertama ditunjuk oleh Bupati Agam adalah bapak MUHAMMAD NASIR, S.Sos. Penjabat Walinagari Persiapan Sungai Cubadak dilantik oleh Bupati Agam pada tanggal 29 Desember 2018.Pelantikan dilaksanakan di SDN 09 Sungai Cubadak.

Pemekaran Nagari Persiapan Sungai Cubadak bertujuan untuk meningkatkan kemampuan penyelenggaraan Pemerintahan Nagari dan pelayanan terhadap Masyarakat serta untuk menumbuhkan peran serta masyarakat dalam Pembangunan Nagari, sehingga dapat mempercepat dan meningkatkan kesejahteraan masyarakat. Dengan potensi sumber daya alam dan sumber daya manusia yang ada di Nagari Persiapan Sungai Cubadak sangat berpotensi untuk mengembangkan pembangunan dan ekonomi masyarakat.

Dilihat dari data diatas penduduk nagari sungai cubadak banyak yang membuka usaha atau wiraswasta dan juga sebagian besar sebagai petani.

Berdasarkan pantauan dilapangan pada daerah baso banyak sekali UMKM, akan tetapi UMKM ini masih kurang sekali pengetahuan mengenai kewirausahaan, pemasaran produk, pembukuan sederhana sehingga UMKM ini lambat perkembangannya, salah satunya di Nagari Cubadak Nagari yang akan masuk dalam Daftar Pemekaran Nagari Baru di Kecamatan Baso.

Banyak pelaku UMKM merasa bahwa perusahaan mereka berjalan normal namun sebenarnya UMKM tersebut tidak mengalami perkembangan. Ketika mereka mendapatkan pertanyaan mengena ilaba yang didapatkan setiap periode, mereka tidak bisa menunjukkan dengan nominal angka melainkan dengan asset berwujud sepertitanah, rumah, atau kendaraan..

\section{PERMASALAHAN}

Sebelum memilih nagari yang akan dijadikan tempat untuk melakukan pengabdian masyarakat, terlebih dahulu kami melakukan beberapa kali survey lapangan ke Kecamatan Baso. Setelah itu barulah Bapak Camat Baso menunjuk Nagari Pemekaran Sungaoi Cubadak Sebagai Tempat kami untuk melakukan kegiatan Pengabdian kepada masyarakat, karena di nagari sungai cubadak ini terlihat sekali permasalahan sebagai berikut :

1. Nagari Sungai Cubadak Merupakan Nagari Pemekaran Baru

2. Masyarakat Nagari Sungai Cubadak Masih Terbelakang

3. Potensi Nagari yang menjanjikan tapi masyarakat belum tahu apa yang akan mereka perbuat.

4. Kurangnya pengetahuan masyarakat tentang kewirausahaan

5. Masyarkat masih belum memahami bagaimana produk mereka bisa dipasarkan.

6. Perhitungan Pembukuan dari usaha yang masih kurang

Berdasarkan permasalahan tersebut, perlu diadakan kegiatan pelatihan bagi pelaku UMKM dalam hal kewirausahaan, manajemen pemasaran dan daya saing produk. Program pelatihan yang ditawarkan berupa pelatihan kewirausahan, fungsi pemasaran bagi UMKM. Metode yang diajarkan

$$
\text { Ekonomi, Sosial, dan Budaya }
$$

1548 
sesuai dengan keadaan di UMKM namun tidak meyimpang dari standar dan peraturan yang ada. Pelatihan ini ditujukan bagi pelaku UMKM yang ada di daerah Nagari Pemekaran Sungai Cubadak Kecamatan Baso. Adanya pelatihan ini diharapkan pelaku UMKM dapat mengetahui perkembangan perusahaan dan dapat memanfaatkan fungsi pemasaran guna mendukung kemajuan UMKM mereka.

\section{METODE}

\section{Kegiatan Pengabdian Masyarakat di NagariPersiapan Pemekaran SungaiCubadak} KecamatanBaso Kabupaten Agam dilaksanakan pada bulan Februari sampai dengan April 2019. Pelaksanaan kegiatan ini dilakukan melalui 2 (dua) tahap. Adapun sistematika pelaksanaan kegiatan pengabdian ini adalah sebagai berikut:

I. Persiapan kegiatan meliputi :

Tahap pertama, tanggal 6 Februari 2019, tim pengabdian masyarakat melakukan kunjungan awal ke daerah di NagariPersiapan Pemekaran SungaiCubadak KecamatanBaso Kabupaten Agam dan melakukan diskusi dengan bapak Wali Nagari dan beberapa pelaku usaha yang ada di daerah tersebut guna mengidentifikasi permasalahan yang dihadapinya. Dari hasil diskusi, ditemukan beberapa permasalahan yang menyebabkan usaha mereka sulit untuk berkembang. Salah satu usaha rumah tangga yang perlu pembinaan khusus adalah Usaha Gelamai Indri.

II. Kegiatan Pelatihan dan Pendampingan

Satu minggu kemudian, pada tanggal 13 - 14

Februari 2019, tim melakukan pelatihan dan pendampingan kepada pelaku usaha di NagariPersiapan Pemekaran SungaiCubadak KecamatanBaso Kabupaten Agam.

(a) Pada hari pertama peserta diberikan materi tentang Motivasi Wirausaha. Tujuannya adalah untuk mendorong dan membangkitkan minat masyarakat Sungai Cubadak untuk berwirausaha.

(b) Sesi berikutnya dilanjutkan dengan memberikan pengetahuan tentang pengelolaan bisnis, pemasaran produk, bagaimana memanfaatkan potensi pasar yang tersedia serta bagaimana meningkatkan daya saing produknya.

(c) Pada sesi terakhir peserta diberi kesempatan tanya jawab dan pemberian door price bagi peserta yang aktif bertanya dan mampu menjawab pertanyaan.

Pelaksanaan kegiatan Pengabdian Pada Masyarakat ini dilakukan juga dengan menggunakan metode ceramah dan diskusi. Adapun sistematika pelaksanaan kegiatan pengabdian ini adalah sebagai berikut:

1. Langkah 1 (Metode Ceramah):

Peserta diberikan motivasi agar memiliki kemauan untuk memahami kewirausahaan, fungsi pemasaran dalam kegiatan bisnisnya. Selain itu, peserta diberikan materi gambaran umum tentang manajemen pemasaran UMKM dan peran penting fungsi pemasaran bagi UMKM. Langkah pertama diselenggarakan selama 1 jam.

2. Langkah 2 (Metode Diskusi):

Peserta pelatihan diberikan kesempatan untuk mendiskusikan permasalahan yang berkaitan dengan pemasaran dan daya saing produk UMKM yang selama ini dihadapi. Langkah ketiga diselenggarakan selama 1 jam.

Berikut ini dokumentasi pada saat dilaksanakan kegiatan pelatihan dan pendampingan pada pelaku usaha di Nagari Persiapan Pemekaran Sungai Cubadak terlihat pada gambar 1,2 dan 3

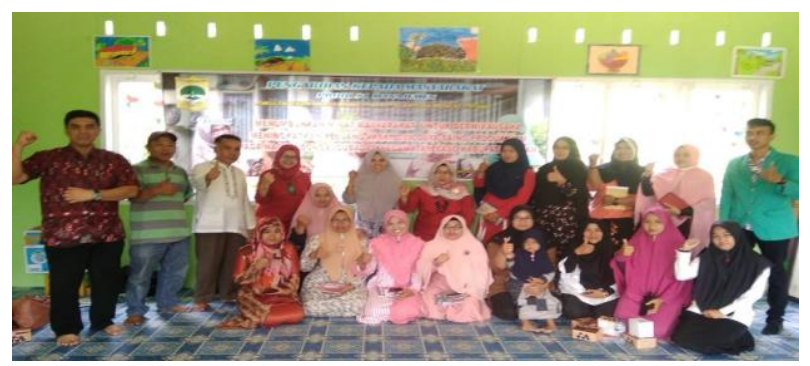

Gambar 1. Foto bersama dengan mitra 


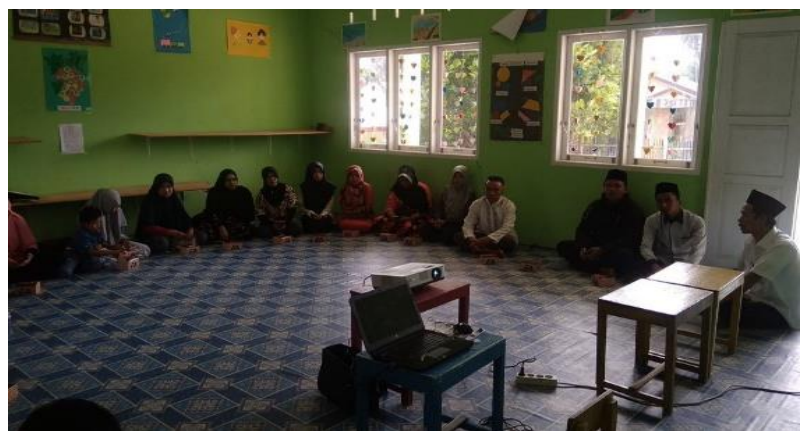

Gambar 2. Foto pelatihan

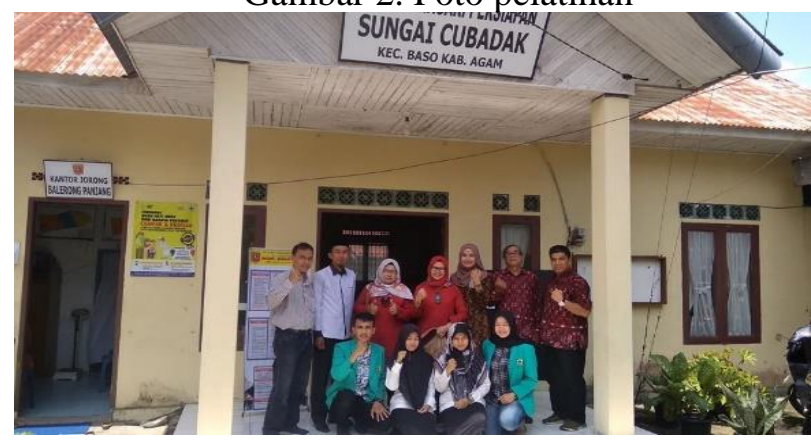

Gambar 3. Foto Bersama di Kantor Sungai cubadak

\section{Solusi}

Solusi yang ditawarkan dalam kegiatan pengabdian berbasis nagari adalah sebagi berikut:

1. Untuk dapat meningkatkan minat berusaha bagi UMKM Tim akan memberikan pelatihan, penyuluhan dan pengetahuan mengenai kewirausahaan

2. Untuk dapat mengerti dengan pemasaran dan produksi tim akan memberikan penyuluhan dan pengetahuan mengenai pemasaran

\section{HASIL DAN PEMBAHASAN}

Kegiatan pengabdian masyarakat ini bertujuan untuk membekali kemampuan dan menggerakkan masyarakat untuk menjadi wirausaha dan juga bagaimana masyarakat dapat meningkatkan keterampilan pelaku UMKM di Baso khususnya di Nagari Cubadak agar dapat menjalankan fungsi pemasaran dengan benar dalam kegiatan bisnisnya sehingga dapat meningkatkan kinerja pemasaran produk usaha mereka. Tujuan pelatihan ini khususnya adalah dalam hal- hal sebagai berikut.

a. Peserta tahu apa itu kewirausahaan

b. Peserta mempunyai minat untuk membuka usaha

c. Peserta mampu dan mengerti dengan fungsi pemasaran

d. Pesertamampu mengerti dengan daya saing produk.

e. Peserta mampu dan punya ide untuk mengembangkan usahanya.

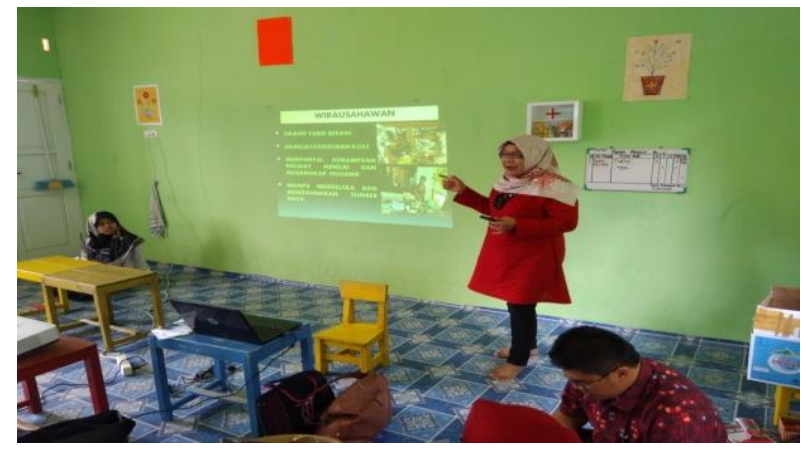

Gambar 4. Foto Sedang Memberikan Pelatihan

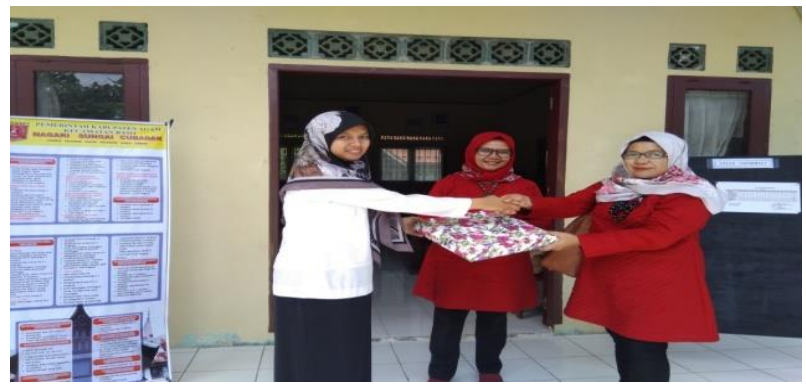

Gambar 5. Kegiatan Pengabdian Pada Masyarakat

\section{KESIMPULAN}

1. Pelatihan yang berbentuk workshop iniberhasil memberikan pengetahuan untuk pedagang usaha kecil menengah mengenai kewirausahaan dan pemasaran.

2. Pedagang usaha kecil menengah ini menyadari dengan adanya pelatihan ini membuat mereka lebih semangat dan mengerti bahwa membuat dan mengembangkan usaha kecil menengah memerlukan pengetahuan lebih, dalam Ekonomi, Sosial, dan Budaya 
kewirausahaan dan pemasaran bukan sekadar berdagang.

3. Sikap rajin, jujur dan terus berinovasi adalah beberapa kunci dari keberhasilan menjadi wirausahawan usahakecil menengah. Namun dengan adanya pengetahuan yang didapat ini sebaiknya ada tindak lanjut menerapkan ilmu kewirausahaan dan pemasaran dalam usaha kecil menengah.

\section{UCAPAN TERIMAKASIH}

Dengan terlaksananya kegiatan ini, kami tim pengabdian kepada masyarakat mengucapkan terima kasih kepada :

1. Bapak Prof. Dr. Deddi Prima Putra, Apt, selaku Rektor Universitas Dharma Andalas Padang.

2. Ibu Dr. Asniati, SE, MBA, Akt, CA, CSRA, selaku Dekan Fakultas dan Bisnis Universitas Dharma Andalas.

3. Ketua LPPM Universitas Dharma Andalas beserta jajarannya.

4. Wali Nagari Persiapan Pemekaran SungaiCubadak KecamatanBaso Kabupaten Agam beserta perangkat dan stafnya yang telah memfasilitasi kami sehingga kegiatan ini bisa terlaksana dengan baik.

5. Teman-teman sejawat yang telah turut andil dalam memberikan ide, masukan dan kritikan hingga terlaksananya kegiatan ini.

6. Dan pihak-pihak lain yang tidak mungkin penulis sebutkan satu persatu, untuk semua yang telah membantu dan memberikan dorongan kepada penulis dalam menyelesaikan kegiatan ini. Terima kasih atas segala motivasi dan saransarannya.

\section{REFERENSI}

Dangayach, G.S., Deshmukh, S.G. (2013). Manufacturing strategy, literature review and some issues. International Journal of Operations and Production

Management.Ciputra, 2009. Ciputra Quantum Leap, Entrepreneurship, Mengubah Masa Depan dan Masa Depan Anda, Alex Media Computindo, Jakarta

Griffin, R. W dan Ebert, R., J, Wardhani, Sita (Translator), Bisnis, Jakarta:Erlangga, 2007

Harefa A, dan Siadari E, E., 2008. The Ciputra Way, Praktik Terbaik Menjadi Entrepreneurship Sejati, Alex Media Cmputindo Jakarta

Kementrian Perindustrian Republik Indonesia, Berita Industri,

Muhardi.(2007). Strategi Operasi. Yogyakarta: Graha Ilmu.

Profil Bisnis Usaha Mikro, Kecil dan Menengah(UMKM),Lembaga Pengembangan Perbankan Indonesia- Bank Indonesia, 2015

Ricky w. Griffin., 2004,Manajemen, Erlangga,

Kasmir.(2017).KewirausahaanEdisiRevisi.Jaka rta:RajawaliPers.

Stanton, William J.1996. Prinsip Pemasaran (terjemahan). Edisi 7,jilid 1.Erlangga. Jakarta. Lamb,Hair,Mc Daniel.2001. Pemasaran (terjemahan).Edisi Bahasa Indonesia,Jilid Pertama.Salemba empat.Jakarta. 201

http://www.kemenperin.go.id/artikel/14200/Ko $\underline{\text { ntribusi-UMKM-Naik }}$ 